\title{
PRACTISING ARCHAEOLOGY WITH COMPOSITE COSMOLOGIES: ON IMPORT AND ALTERNATION IN THEORY
}

Niels N. Johannsen

Aarhus University

Department of Archaeology

Moesgaard Allé 20, DK-8270 Højbjerg, Denmark

nnj@cas.au.dk

I found Gavin Lucas's meta-theoretical reflection on flows and levels in theory and theorizing an inspiring and encouraging read. Configurations and behaviours in those dimensions of our intellectual matrix addressed by Lucas are extraordinarily consequential for the practice of archaeology, and I am very sympathetic to the way he chooses to tackle them, just as I am to several of his conclusions. There are many facets to Lucas's essay, but my comments will focus on what I see as its two central problematics, between which Lucas deftly identifies a connection: (I) the import and appropriation of theoretical resources into archaeology, potentially in contrast to their internal development, and to export, and (2) the roles played by different levels of theory, specifically the issue of top-down vs. bottom-up flows in inferential practice.

Lucas notes how many archaeological discussions of intellectual inspiration from outside the discipline pitch the import of theories against internal, "home-grown" theory building, and that they usually involve underlying presumptions that one or the other is more or less desirable. Lucas, very productively, steps back a little from such normative evaluation and instead targets how theoretical appropriation and accommodation take place in practice. Starting from his experience of working in an abandoned Icelandic village, he makes the observation that 
not only theories but also techniques and methods are really composite phenomena, often integrating elements of widely varying intellectual and practical origins. This general, cross-domain compositionality of the resources we work with leads Lucas to argue that theory building and theory borrowing are in practice closely intertwined: theory is mobile, and at least the former could not exist without the latter. I agree entirely. From this point of view, warnings against free uptake of nonarchaeological inspiration in the discipline are like well-intended warnings that students should be wary of theoretical eclecticism (to avoid inconsistencies and logical contradictions) - despite the fact that none of the esteemed theoretical works they are assigned to read, whether archaeological or not, could have been produced without it.

But something I missed in Lucas's paper, which he deliberately leaves aside and which most discussions in our discipline steer clear of, is an actual confrontation with the question of why we seem driven to bring all these apparently non-archaeological intellectual resources into archaeology. What is it that these imported perspectives do for us? Of course it is possible, in retrospect most often, to point to wider intellectual, political and economic currents that potentially explain a given episode of inspiration (e.g. Thomas 20I2) - but such analyses rarely explain much about the phenomenon of theoretical import in general or its profile in archaeology. However, a consideration of why (in addition to how) will have direct implications for our understanding of an issue that Lucas does confront more directly, namely the question of what has given many the impression that our trade balance with other disciplines is so skewed? Is it simply inferiority complex, or just a long historical absence of appropriate effort internally in our discipline, as lamented already by Binford, Clarke and others half a century ago? Or something else?

I would like to ask the question whether perhaps, in many cases, the theoretical work we import is work that does something better than we as archaeologists could ourselves? I don't mean because we lack creativity, enlightenment or good training, but because the particular affordances of our empirical substance and the corresponding qualities that dominate our methodological and epistemological enculturation has a limited set of strengths compared to the total scope of our study. This question could, of course, immediately ring the bell for another wrestle with Hawkes's ladder - and indeed that might not be such a bad thing. But let me start by noting what seems to me a slightly paradoxical integration of two interdependent trends in our disciplinary landscape:

Firstly, the import of theoretical perspectives from other disciplines hardly seems on the decline. Indeed, just as it was throughout the postprocessual era, and to some extent before that, most contributions to 
archaeological theory being published - as far as I can see - still depend on large amounts of non-archaeological theory. This picture includes so-called New Materialist perspectives, which themselves claim exemption from this pattern on the basis of a reduction in time delay, by comparison to earlier trends, between the publication of the non-archaeological sources inspiring and the archaeological works inspired (cf. Olsen 20I2). At the same time, though, the dominant theoretical spirit of our discipline, now and similarly throughout recent decades, seems to have maintained a staunch conviction that with the right selection of material, methods and theory, archaeologists have as much to say about such things as human belonging, conceptualization, emotion, learning, polysemy, religion or violence as do ethnographers, linguists, psychologists, sociologists or others researching "living" cultures, activities and human subjects - just in our own archaeological way, of course. At a superficial level, perhaps the clearest general manifestation of this spirit is the plethora of book and paper titles that go "The archaeology of...". So, we seem to be insatiable consumers of other disciplines' attempts to work with such topics and at the same time unbent optimists about the prospect of working competently with them on our own terms. Questioning this valiant spirit has for long not seemed popularly compatible with any status of theoretical enlightenment and sophistication (in fact doing so might compete favourably for the worst thinkable way of making oneself popular within any community of theoretically informed archaeologists). And it is indisputable that many archaeologists would like to say something about these aspects of past. But is the optimistic tenet justified, or at least productive?

On the one hand, the answer clearly seems yes. From my perspective, all included in the somewhat random selection listed above are valid and interesting themes for archaeology (and I work with some of them myself). The simple fact is, of course, that if "we" don't deal with them - working under the conditions that we do - we can be sure that considerations of their variation, role and significance in the vast majority of our human past will be detached from any qualified consideration of what empirical link we have with past people and culture. And that hardly seems like an attractive scenario. On the other hand, I can't shake the feeling that the notion of potential archaeological success in covering most of the ground covered by various parts of all the other cultural and social sciences, if not carefully qualified, is less a well-based confidence than defiant denial of basic conditions at the core of our discipline. And the qualification needed may point to at least one of the factors explaining the evidently strong attraction of "outside theory" to archaeology: archaeologists are in general well trained to deal with many dif- 
ferent aspects of human life and culture, but scholars working in other disciplines have more favourable starting points for dealing with some of them. What I mean is that any body of theoretical work we adopt or "borrow" from another discipline was in general produced with and through a particular set of empirical resources, methods and analytical norms typical of that discipline - that is, this work was conditioned by its full empirical-epistemological nexus. What attracts us to the work of other disciplines is that their particular empirical encounters allow different, in some cases richer understandings of particular phenomena.

Here it might be useful to recall that some of the most prominent contributions to archaeological "theory building" (following Lucas's distinction) were made when archaeologists deviated from observation and analysis based mainly on archaeological material. Both Binford and Hodder, with their students, made ground-breaking contributions to the interpretive cosmology of archaeology by working as ethnographers. Ethnographers with archaeological questions and priorities concerning material culture and the formation of the so-called archaeological record in mind, yes, but as ethnographers none the less - in empirical, methodological and epistemic modes that are substantially different from those involved in most archaeological fieldwork. Despite all the challenges associated with uniformitarian assumptions and analogies more broadly in the study of culture, their respective programmes were - indisputably, I think - very productive, mainly for archaeology. While these are generally and justifiably perceived as instances of theory building in archaeology (cf. Lucas), much of the work that provided the decisive data was not distinctly archaeological.

The point I am building up here is not that in order to develop - rather than simply consume - theory in archaeology we necessarily need to switch to the analytical modes of other disciplines, be it ethnography or some other genre. This is just one of several potential ways. But such cases of analytical shape-shifting bring out clearly how different ways of working have different inferential potentials, and these differences have implications in understanding the more widespread and sometimes subtler import of "ready-made" non-archaeological theory. What I want to draw attention to is the fundamentally double-edged quality of the theoretical goods we import. Using theory developed in other disciplines allows us, ideally, to capitalize on the strengths of their particular modes of encountering the ontological fields that we seek to understand. But, just as much, along with the strengths of these modes, we also get their limitations - and the modal differences between "theirs" and "ours" cause problems of integration. Looking to academic fields that centre on more formalized and explicit attempts at interdisciplinary exchange and 
cooperation may provide a clearer exposure of what these challenges of integration might look like.

One such example is the culture and cognition field, which sees a complex meeting of disciplines from the humanities and social sciences (including archaeology) with those of the cognitive and behavioural sciences. On the one hand, in this case there are clear commonalities of interest and problems to solve, just as there is a sense of mutually potent complementary between the empirical and analytical resources of both sides - promising, for instance, the prospective yields of reciprocal dialectics between ideographic and nomothetic views of the same phenomena (as Lucas emphasizes, casting preoccupations with the specific and the general as opposed or clearly separable pursuits to some extent obscures actual intellectual behaviour). On the other hand, in practice it has proven difficult to integrate the very substantial scientific bodies generated by the former disciplines, i.e. their empirical records, knowledge and understandings, with most contemporary approaches and results in the latter disciplines' study of the mind (Astuti \& Bloch 20I2). Among the main challenges are not only different notions of what constitutes evidence and knowledge but, perhaps even more significantly, the problem that researchers are enculturated into completely different scales of analyses - that produce fundamentally different ways of thinking about causation (Johannsen et al. 20I4). Archaeology, at its best, has the ability to straddle many different scales of analysis - from the close attention to micro-level patterns (e.g. Fahlander 2003) to the longest durées of human prehistory, spanning millennia. Macro-scale perspectives are a distinct part of archaeology's cosmology, but thinking academically at such scales is in fact a highly counterintuitive, intellectually challenging exercise that in general requires a specific kind of focused enculturation (training). The temporal macro-scale in particular violates many of the intuitions we are given as individuals by the proximal scales of our subjective experience, and by the duration of our lifespans and the relationships within them (cf. Costal 2006). In addition, scholars trained to think predominantly at micro- and meso-scales often assume that smaller scales simply debunk large-scale accounts of society, history and evolution by showing "what is really going on". An alternative view is that macro-scale accounts capture equally significant causal relationships that simply are not visible at smaller analytical scales (e.g. Edwards 2003; Sztompka 1994). Both personal and professional biases of scale are in general forgotten by the thoroughly enculturated archaeologist, for whom a particular cosmology is long established - and the same of course goes for any other academic, each with the general cosmology of her particular discipline at least partly internalized. While 
such differences between professional cosmologies may seem very basic, their epistemic impact is hard to overestimate.

This example underscores Lucas's point that our main challenge is not our constant inspiration and sometimes reformation by imported goods but that of integration. Julian Thomas has made the same point: "... it does not particularly matter if some of our theoretical inspiration comes from beyond our own disciplinary confines. What does matter, though, is the intellectual labour necessary to make those ideas compatible with our focus on the material worlds that human beings inhabit and how these change through time" (2015:22-23). But to Thomas this implies that the complaint about too much import and too little internal development of theory is "something of a red herring" (2015:22). While I agree with the former, I think that the latter (herring part) is true only if the former condition is met - that is, if at least most of the time we actually do succeed in making those "outside" ideas compatible with our material and focus, rather than the other way around. And on that score I think that our track record is not entirely favourable. Steven Shennan once complained about a proliferation of "prehistorians as ethnographers manqués of the prehistoric present, struggling to achieve a goal which [...] is unattainable, and failing to get as far as the questions of long-term change which are supposed to be archaeology's privileged domain" (I989:330-33I). Reading contributions to archaeological theory from across the whole "post-innocence era", I am probably not the only one who has, more than a couple of times, had a similar feeling that it was not the archaeological author who was going somewhere with a nonarchaeological source of inspiration, but vice versa. Of course, getting carried away by the latest or biggest thing in some other discipline is not inherently negative; it may in some ways be very productive. But it does not necessarily promote theoretical perspectives in which archaeological data and training play any particularly strong part.

One relevant example from our very recent disciplinary history might be the introduction of "inanimate agency" perspectives in archaeology, in which some of the standard-bearing papers featured a very clean, fullthrottle adoption of a particular perspective developed outside archaeology (the ANT doctrine of "symmetry"). In some cases there was no detectable archaeological processing of the imported framework (e.g. Olsen 2003), which was sometimes followed down to close mimicry of the role model's rhetorical style (e.g. Webmore \& Witmore 2008). While this adoption was argued with reference to an apparently intimate compatibility with the character of archaeology's empirical substance, the founding assumptions of the philosophy adopted had been developed not in the study of material culture or technology but in the study of 
language within post-structuralist semiotics. As noted by several critics (Barrett 20I4; Glørstad 2008; Johannsen 20I2), the resulting perspective did not seem to reflect any clear sensitivity to what archaeological data and modes of analysis might contribute to understandings of agency and causality more broadly; indeed the latter would seem to inspire perspectives very different from those of "symmetrical" accounts.

Lucas suggests that the type of worry I have just voiced and exemplified is mainly the product of a widespread, artificial separation of techniques (which are less risky to import) and theories (which are more risky, carrying all the baggage I have described above). While I do think that many of the theoretical resources commonly imported in archaeology carry much further-reaching complexes of ontological commitment than the naked "concept metaphors" emphasized by Lucas, I agree with him that imported techniques do not necessarily represent less of a challenge to us than imported theories. But I do not think that this point in any way detracts from the observation that we have often failed to let ourselves, as archaeologists, be in charge when developing archaeological theory (cf. Edgeworth 20I2). I would like to dismantle our alleged inferiority complex in a different way: when many experience a skewed trade balance it is probably for two interconnected reasons; many archaeologists have simply been very interested in things that other disciplines are better equipped to work with, and many of us have not focused sufficiently on integrating theoretical imports. David Clarke classically pointed out that the price of transitioning from theoretical innocence to critical self-consciousness was a restless state of eternal, unfulfilled vigilance (1973:I2). Contrary to what Clarke may have hoped for, it could be argued that history has added another significant expense incurred from the rising status of theory in archaeology, namely a tendency towards clientization of the archaeological intellect. If theoretically informed archaeologists have often attempted to play the particular games of other disciplines, only with means less suited, it is hardly surprising that those attempts have rarely aroused a storm of fascination and intellectual consumption in our neighbouring disciplines.

Now, there have been many theoretical efforts in archaeology which were highly important and valuable within our discipline without necessarily having much aspiration or appeal for an interdisciplinary audience; the Binfordian "middle range" programme to which Lucas rightfully devotes attention is just one example. But when it comes to playing a significant intellectual role in other parts of the academic landscape the bar is raised or, perhaps rather, specified: archaeology will be a contributor to the general theoretical framework for understanding humans and their culture only to the extent that it can provide insights that are 
made best through the practice of archaeology (rather than some other discipline) - and here I include work in which archaeologists cooperate with other disciplines in analysing archaeological material (as, for instance, those emphasized by Kristiansen 20I4). This does not entail reducing the intellectual space for "non-archaeological" resources in our epistemic community - as argued by Lucas, there never could be purely archaeological theory. But it does involve nurturing a distinct tuning towards what these resources integrated with the strengths of archaeology can do for us, archaeology in particular as well as the wider study of humans and culture in general. In other words, it requires a professional cosmology that is continuously composed of a variety of influences yet remains distinctly archaeological. While there is no particular reason for privileging, for instance, archaeological understandings of causality over others (just like virtually all social scientists, we are ill-equipped to provide strict or simple accounts à la "billiard ball causation"), discernibly archaeological contributions to the interdisciplinary smorgasbord in this case would be inferences and perspectives informed by a broader intellectual context but afforded specifically by our empirical substance, analytical possibilities and epistemological enculturation - for example understandings of how the downstream effects of human action play out over longer time spans. While those who would like to see archaeology as the "discipline of things" have very different notions of what our particular "ecology of practices" does best (Olsen 20I2; Olsen et al. 20I2; Witmore 20I4; Witmore \& Shanks 20I3), archaeology is for many archaeologists at least as much the discipline of time (e.g. Lucas 2005) and, pardon, cultural process. Whichever identity one prefers, the integrative tuning just emphasized will be decisive in defining the interdisciplinary attractiveness of archaeological thought and, in turn, the profile of that notoriously troubling trade balance. Variants of such a skill can be promoted in the education of new archaeologists, but beyond that I do not think there could be any overall strategy, politic or philosophical doctrine for successful integration. In my view it is, above all, a challenge for the individual scholar or team of scholars - and that leads me to the second and related main issue of Lucas's paper.

Lucas identifies the problem of import discussed above as partly connected to different (perceptions of) theoretical levels or starting points in inferential practice: historically, theoretical import and a strong topdown profile in concrete analyses have often been connected (I provided one recent case above), and both can lead to archaeological material becoming marginalized. As Lucas notes, the current climate in thinking about such levels is unmistakable: there is a clear trend in favour of emphasizing "bottom-up" directionalities in inference and theoriz- 
ing, which probably sees its most radical expression in archaeology among adherents of the "New Materialist" development (e.g. Olsen 20I2; Olsen et al. 20I2; Witmore 20I4). While acknowledging in passing that we cannot abolish "interpretation in its modest and inevitable form" (Olsen 20I 2:22), the revolutionary-flavoured rhetoric of this movement cracks down hard on the allegedly rampant deflowering of non-human materiality that has long resulted from the decadent pawing of over-intellectualizing academics (with one thing on their mind: interpretation). New Materialists propose that a programme for working more intuitively and immediately with concrete things should supplant the highbrow theorizing that has long held supremacy in the humanities and social sciences. In this programme specifically and the broader climate more generally, as Lucas indicates, "top-down theorizing has almost become a dirty word". Lucas is quick to note that some "vicious critic" might fail to see how there is anything "less top-down" about the way that these scholars actually engage with archaeological material and one might even claim their programmatic statements to constitute prime exemplars of attempted top-down regulation - though in reply Lucas points to examples of performative archaeology that experiments with "non-representational" ways of working (by which he apparently means work that mainly represents itself through other media than text).

Vicious or not, Lucas proceeds to argue for a perspective that is at least as much in line with the imagined critic as with the latter's New Materialist or "neo-empiricist" victims. Building from an extended discussion of middle range theorizing and levels of generalization, he suggests that top-down flows - just like bottom-up flows - are unavoidable, and that both of them should be able to coexist with a focus on and confidence in the contribution of our archaeological material, methods and overall practice. I fully agree with Lucas on these pivotal points. What puzzled me was how Lucas immediately deflates his own criticism of the current bottom-up dogma by suggesting that we might avoid thinking of theorizing in terms of hierarchies of abstraction or generality altogether, i.e. that a focus on intellectual practice will "flatten everything out". Flattening various things has become surprisingly popular (following DeLanda 2002), considering its tendency to produce causal anonymity rather than the very demanding processual accounts originally intended, and Lucas's vicious critic might be back to protest that what has distinguished the whole idea of a "flat" ontology from its more broken alternatives when put into analytical action has mainly been its dependence on what Jack Goody (2000:9) once called "porridge functionalism" i.e. the analytical centring of the non-committal principle that everything influences everything else in largely unspecified ways. Whatever 
the case, if I understand correctly what Lucas is trying to achieve with this manoeuvre, I am sympathetic: he appears to suggest that a focus on concrete, localized practices of theorizing could shift the whole discussion to a more productive angle. I agree. But in the end I felt that the deflationary effect of his "flat" conceptualization leads Lucas to leave the central problem he identifies underappreciated.

Many of the difficulties discussed here arise from the whole assumption, which Lucas (despite his appeal to localization) appears to share with his New Materialist colleagues, that the configuration of bottomup/top-down starting points, levels or flows in inference and theorizing is something we can decide on as a discipline, i.e. a controllable field of practice for which we can devise a kind of research strategy or politic based on a given philosophical position (as in "we have decided to work bottom-up", "top-down" or "more/less" of one or the other). To me this assumption seems plainly out of tune with intellectual realities, and I am fundamentally sceptical of any programmatic attempt to control or direct our foraging patterns up and down the continuum of cognitive foci and zoom levels, in terms of both feasibility and productivity. Top-down cascades in our intellectual processes are not only "impossible to avoid so long as we want to maintain some kind of shared disciplinary space with other fields", as emphasized by Lucas, but impossible to avoid in any kind of engagement with archaeological material. The challenge of allowing one's intuitions, hypotheses and theories to guide exploration of what one wishes to understand while remaining open to whatever the empirical substance explored actually has to offer is a fundamental tension faced by any individual researcher and collaborative team. It is, in practice, basic to all processes of inference in archaeology (and beyond), as Ian Hodder has shown with particular clarity (I999). Navigating this alternation between openness and closure is a continuing challenge at many different scales; in the immediate encounter with an object, through unfolding excavations and research projects and across entire careers - and it goes all the way down to the most basic operational premises of our discipline. Seeing a "posthole" as a posthole (an ability cognitive scientists sometimes refer to as "categorical perception") is not something given but something learned. Like a host of other learned assumptions, it forms part of what Charles Goodwin (I994, 20I0) has called a "professional vision", into which young archaeologists are gradually enculturated. Such a vision is both empowering and potentially constraining; without it we could never go beyond the state of perplexity caused by seeing everything we encounter as novel and unique, but without simultaneously allowing variation, novelty and surprise, and without the ability to challenge basic categories from time to time, we 
would be equally paralysed. From grand theory to minute pattern recognition, we carry abstraction, categorization and intellectual prejudice with us all the time; and it works surprisingly well.

Gavin Lucas's thoughtful discussion made me realize fully just how little the current celebration of bottom-up flows in academic thought is doing to preserve what should have been the most basic and enduring epistemological lesson of the post-modern era (cf. Fahlander 20I2; Holtorf 20I2). Just as we cannot be exempt from interpreting and intellectualizing our academic practices (as formalized here), there is no way of stepping out of such practices of abstraction and intellectualization when engaging with the material we study - or any other part of the world. Post-humanist aspirations notwithstanding, and regardless of what one thinks the aims of archaeology should be, we are humans studying things; not the things studying themselves on what would genuinely be their own terms. As the cross-cultural empirical records of archaeology, ethnography, history, linguistics and psychology make amply clear, abstraction, classification and contextualization are not an invention of modernity, or post-modernity for that matter. We have never (just) been immediate - nor is there much prospect that we will become so. The proposal that we can strategically minimize our pre-existing human concerns and priorities and let our engagements with things work, for more than an instance, more or less entirely from the bottom and almost without the former, seems a very close philosophical neighbour to that which sustained hard-line positivism: the presumption that we could lay them aside to obtain that coveted, neutral God's Eye View. But for all the extensions of human perception made possible by our battery of scientific instruments, in epistemic terms we remain fundamentally stuck with the Human's Eye View. The Thing's Eye View, just as much as the God's Eye View, is an illusion to anyone born human. And for that reason the current allusions to studying things without massively imposing our abstractions upon them (Olsen 20I2) or to writing history "from the point of view of the things rather than the people" (Thomas 2OI 2:87) seem ironically anthropocentric - less an act of standing back and giving space than perhaps the most radical claim for human intellectual omnipotence so far.

\section{REFERENCES}

\section{Literature}

Astuti, R. \& Bloch, M. 20I 2. Anthropologists as Cognitive Scientists. Topics in Cognitive Science. Vol. 4(3). Pp. 453-46I. 
Barrett, J. C. 20I4. The Material Constitution of Humanness. Archaeological Dialogues. Vol. 2I(I). Pp. 65-74.

Clarke, D. L. 1973. Archaeology: The Loss of Innocence. Antiquity. Vol. 47. Pp. 6-I8.

Costall, A. 2006. On Being the Right Size: Affordances and the Meaning of Scale. In: Lock, G. \& Molyneaux, B. L. (Eds). Confronting Scale in Archaeology: Issues of Theory and Practice. Pp. I5-26. New York: Springer.

DeLanda, M. 2002. Intensive Science and Virtual Philosophy. London: Continuum.

Edgeworth, M. 20I 2. Follow the Cut, Follow the Rhythm, Follow the Material. Norwegian Archaeological Review. Vol. 45(I). Pp. 76-92.

Edwards, P. N. 2003. Infrastructure and Modernity: Force, Time, and Social Organization in the History of Sociotechnical Systems. In: Misa, T. J., Brey, P. \& Feenberg, A. (Eds). Modernity and Technology. Pp. I85-225. Cambridge, MA: MIT Press.

Fahlander, F. 2003. The Materiality of Serial Practice. A Microarchaeology of Burial. Gothenburg: University of Gothenburg.

Fahlander, F. 20I2. Are We There Yet? Archaeology and the Postmodern in the New Millennium. Current Swedish Archaeology. Vol. 20. Pp. I09-I29.

Glørstad, H. 2008. Celebrating Materiality: The Antarctic Lesson. In: Glørstad, H. \& Hedeager, L. (Eds). Six Essays on the Materiality of Society and Culture. Pp. I732I I. Gothenburg: Bricoleur Press.

Goodwin, C. 1994. Professional Vision. American Anthropologist. Vol. 96(3). Pp. 606633.

Goodwin, C. 20Io. Things and Their Embodied Environments. In: Malafouris, L. \& Renfrew, C. (Eds). The Cognitive Life of Things: Recasting the Boundaries of the Mind. Pp. I03-I 20. Cambridge: McDonald Institute for Archaeological Research.

Goody, J. 2000. The Power of the Written Tradition. Washington DC: Smithsonian Institution Press.

Hodder, I. 1999. The Archaeological Process. Oxford: Blackwell.

Holtorf, C. 20I2. No Farewell to Interpretation. Current Swedish Archaeology. Vol. 20. Pp. 57-60.

Johannsen, N. N. 20I2. Archaeology and the Inanimate Agency Proposition: A Critique and a Suggestion. In: Johannsen, N., Jessen, M. \& Jensen, H. J. (Eds). Excavating the Mind: Cross-sections through Culture, Cognition and Materiality. Pp. 305-347. Aarhus: Aarhus University Press.

Johannsen, N. N., McGraw, J. \& Roepstorff, A. 20I4. Introduction: Technologies of the Mind. Journal of Cognition and Culture. Vol. I4(5). Pp. 335-343.

Kristiansen, K. 20I4. Towards a New Paradigm? The Third Science Revolution and its Possible Consequences in Archaeology. Current Swedish Archaeology. Vol. 22. Pp. II 34 .

Lucas, G. 2005. The Archaeology of Time. London: Routledge.

Olsen, B. 2003. Material Culture after Text: Re-membering Things. Norwegian Archaeological Review. Vol. 36(2). Pp. 87-ro4.

Olsen, B. 20I 2. After Interpretation: Remembering Archaeology. Current Swedish Archaeology. Vol. 20. Pp. I I-34.

Olsen, B., Shanks, M., Webmoor, T. \& Witmore, C. 20I 2. Archaeology: The Discipline of Things. Berkeley: University of California Press. 
Shennan, S. 1989. Cultural Transmission and Cultural Change. In: van der Leeuw, S. E. \& Torrence, R. (Eds). What's New? A Closer Look at the Process of Innovation. Pp. 330-346. London: Unwin Hyman.

Sztompka, P. 1994. Evolving Focus on Human Agency in Contemporary Social Theory. In: Sztompka, P. (Ed.). Agency and Structure: Reorienting Social Theory. Pp. 25-60. Amsterdam: Gordon and Breach.

Thomas, J. 20I 2. A British Perspective on Bjørnar Olsen's “After Interpretation”. Current Swedish Archaeology. Vol. 20. Pp. 83-88.

Thomas, J. 20I5. Why 'The Death of Archaeological Theory'? In: Hillerdal, C. \& Siapkas, J. (Eds). Debating Archaeological Empiricism: The Ambiguity of Material Evidence. Pp. I I-3 г. New York: Routledge.

Witmore, C. 20I4. Archaeology and the New Materialisms. Journal of Contemporary Archaeology. Vol. I(2). Pp. 203-224.

Witmore, C. \& Shanks, M. 20r3. Archaeology: An Ecology of Practices. In: Rathje, W., Shanks, M. \& Witmore, C. (Eds). Archaeology in the Making: Conversations through a Discipline. Pp. 380-398. London: Routledge.

Webmoor, T. \& Witmore, C. L. 2008. Things Are Us! A Commentary on Human/ Things Relations under the Banner of a 'Social' Archaeology. Norwegian Archaeological Review. Vol. 4I(I). Pp. 53-70. 